\title{
On Fulfillment: Uncovering the Possibility of a New Objective Insight
}

\section{Paul Gyllenhammer}

Marquette University

Edmund Husserl's Logical Investigations provides the framework which guides this presentation.' That framework revolves around the analysis of a subject's empty intentional act meeting with an object in a moment of filfillment, where fulfillment is the occurrence of insight or knowledge. Husserl's theory of fulfillment, although promising a lot, does not deliver on all its promises. In particular, we highlight two problems which foil Husserl's attempt to account for the notion of fulfillment. From these problems, we show how Paul Ricoeur's interest in the te.tt and narrative, although changing the focus of Husserl's analysis, makes possible the framework set up in the Logical Investigations.

The first problem relates to the issue of an intersubjective grasp of the external world. Husserl's notion of fulfillment implies an intersubjective component but fails to account for it given his focus on the solitary life (Seelenlehen) of the speaking subject. As means to free us from this limitation, we encounter Ricoeur's notion of the text.

The second problem stems from Husserl's inability to deliver on his productive notion of fulfillment. To show this, we must first explain that fulfillment can be understood from two different levels: static and dynamic. On the static level, Husserl explains that the subject's grasp of meaning-a consciousness of identityis not productive since what the subject comes to know is a meaning already operative in the subject's pre-reflective life. On the dynamic level, the subject can be said to gain a new' insight into the world thus highlighting a productive sense of fulfillment.

Although this productive sense of fulfillment promises to open the subject to new' objective insights, Husserl's solipsism makes dynamic fulfillment an inoperable notion. As an answer to this problem, we turn to Ricoeur's notion of narrative and show how productive fulfillment can occur. 
Before we get the analysis underway, a brief explanation is in order regarding my treatment of Husserl. The reader who is familiar with Husserl's corpus, especially the Cartesian Meditations, ${ }^{2}$ will be quick to respond that Husserl is concerned with incorporating into his phenomenology the very issue of intersubjectivity which concerns my analysis. The fifih meditation, in particular, is devoted to showing how the notion of objectivity depends upon intersubjective constitution. ${ }^{3}$ Husserl's interest in intersubjectivity is an indisputable fact. What is in dispute is whether or not Husserl successfully overcomes the solipsism which looms over his earlier writings: the Logical Im estigations and Ideas ${ }^{+}{ }^{+}$That these texts suffer from the problem of solipsism seems to be no less of a fact. I am not, however, interested in Husserl's capacity to overcome his own shortcomings in this paper. It is a thematic problem which concerns me: how a new' objective insight is possible for the subject. Thus, if my treatment of Husserl is deemed as overly narrow let me state that it is for the greater good of locating an issue which I believe Ricoeur clearly sees and to which he provides a plausible answer.

\section{Solipsism and the Static Notion of Fulfillment}

Fulfillment is a term which is supposed to account for more than how an isolated ego grasps the object of perception. When fulfillment occurs the subject has an insight regarding how the object must be for all people. The moment of fulfillment, then, is correlated to a universal insight. Husserl's concern for a universal perspective, however, is immediately put into question given 1) his exclusive focus on the speaker's grasp of his or her own intentions and 2) his explanation that a subject's intention is influenced by previous experiences with the object of perception." The problem which follows is this: if an individual's intentional grasp of an object is influenced by prior experiences with the object, and if the analysis never moves outside of the individual's own grasp of the object, then the scope of what the individual can know' of the object is limited by his or her real world experiences. So, although we can admit that the subject knows an object through experience, we cannot say that this level of insight is a universal insight regarding how the object must be for all people.? 
By itself, the solipsistic perspective requires us to, at least, build into the analysis of intentional experience an intersubjective perspective. Before we do this, we would like to uncover some of the structural components and terminology which make up Husserl's notion of fulfillment. For Husserl's account points to the way in which the intersubjective dimension can be addressed. We see this potential for advancement in Husserl's idea that the notion of fulfillment can be productive.

The notion of fulfillment has a productive dimension to it. This is made plain when Husserl says that individuals can gain an awareness of meanings. But Husserl's appeal to a new' awareness of meaning can be misleading since this productive dimension can be taken in two senses. Here we concentrate on the first (and limited) sense of productivity. It correlates to a person who through reflection becomes aware of meanings which are already operative in his or her dealings with the world. In this sense, a subject gains a new' awareness, or, as Husserl says, a consciousness of identity.

Only when we use the perceptual series to found a novel act, only when we articulate our individual percepts, and relate their objects to each other, does the unity of continuity holding among these individual percepts-the unity of fusion through their coinciding intentions-provide a grounds [Anhalt] for a consciousness of identity.... Our act of identification is in sober fact a new awareness of objectivity, which causes a new 'object' to appear to us... (LI, 791; translation modified).

Husserl appeals to a new' awareness of the object but such an awareness is new' only for the person and not in reality. The subject explicitly grasps what is already in play on a pre-reflective level. Let us clarify this dimension of experience by applying some of Husserl's terminology to this level of insight. In particular, we look at the notions of static (statische) and dynamic (dynamische) fulfillment as based upon the empty/full paradigm (LI, 687-694). 
A static moment of fulfillment is described by Husserl as the tranquil correlation between intention and object (ein ruhendes Erfïlltsein, nicht ein sich Decken, sondern das in Deckung Sein [LI, 696]). This level of fulfillment is best described as a subject's unreflective dealings with an object of perception, e.g., when a person who is looking for a particular object finds it in perception and says, "There is my inkpot." In such an instance, Husserl would say that the object of the intention is the focus and not the components which make up the intention.

Through reflection, however, the aspects which make the act intentional can become the object of focus. These parts are, minimally, the subject's grasp of an object and the object's presence. Husserl goes on to describe the subject's intentional grasp as empty and the subject's actual perception of the object as a moment of intuitive fulfillment.

We must pay special attention to the notion of emptiness at this point, for Husserl is not referring to a mere nothingness. Rather, the term emptiness points to the mind's grasp of the object which exceeds what is actually given in perception. So, the term emptiness describes the mind's grasp of those aspects of the object which are currently absent but which could be brought into view at another point in time. (Please keep this account of emptiness in mind since it will be contrasted with another kind of emptiness later in the presentation. ${ }^{8}$ )

Now that Husserl has us reflecting about the components involved with the notion of fulfillment, he changes the terminology from static to dynamic fulfillment. That is, when a person stops to dissect the components involved with a tranquil or static moment of fulfillment, the separation between intention and intuitive moment is revealed. In reflection, we can say that the intention meets with its object as if the intention were like a moment of expectation which finally reaches its object (LI, 700). Such a meeting is described by Husserl as a dynamic moment of fulfillment.

We must emphasize that this separation is in thought and not in reality. The intentional grasp which is described by Husserl as an empty act, and the corresponding intuitive act which fulfills the emptiness, are not two separate acts but moments which make one 
act unified. As Husserl says, "Talk about recognized objects, and talk about fulfilling a meaning-intention, therefore express the same fact, merely from differing standpoints. The former adopts the standpoint of the object meant, while the latter has the two acts as its foci of interest" (LI, 695).

The point is that even though in reflection it is possible to distinguish between static and dynamic fulfillment, between the intentional state of being fulfilled and the conditions which make this state possible, what we have here is just two different perspectives on the same act. So, when Husserl says that in reflection the subject gains an awareness of the object of thought versus the object of intuition, where the object of thought is likened to a consciousness of identity, this awareness is not productive in the sense of an addition. When Husserl refers to a new awareness of the object-a consciousness of identity-we cannot take him to mean new' in the sense of never experienced before; rather, Husserl means $n e w^{\prime}$ in the sense of becoming reflectively aware of something which is already known to the subject at a deeper, more fundamental, level (LI, 790).

At this level, Husserl's analysis of fulfillment is concerned with a static model of knowledge. In other words, Husser]'s account is based upon a level of subjective awareness which is already settled, where a subject already grasps the object from previous encounters and, even if the components involved with the intentional act are brought into focus through reflection, nothing new' is learned about the world which was not already a part of the subject's intentional life.

There is, however, a second reading of the notion of dynamic fulfillment which promises to open the subject to new insights about the world. It is this account which holds our attention for it promises to break the circle of familiarity which has taken the productive life out of the subject's intentional field of awareness.

\section{Dynamic Fulfillment as Productive}

Alongside this static analysis of the subject's grasp of meaning, Husserl implies that a subject can gain an insight into the world which is totally new. This perspective is best seen when Husserl refers to the limits to the human capacity to know. Husserl says, 
Wherever a new concept is formed, we see how a meaning becomes realized that was previously unrealized.... [Meanings] are an ideally closed set of general objects, to which being thought or being expressed are alike contingent. There are ... countless meanings which ... are merely possible ones, since they are never expressed, and since they can, owing to the limits of man's cognitive powers, never be expressed (LI, 333).

Two ideas jump out at us in this passage. First, Husserl refers to the formation of a new' concept which helps a person realize a meaning that was previously unrealized. Second, Husserl refers to the countless meanings which are simply inaccessible to humans because of the "limits of man's cognitive powers." If we take this second claim, in light of the first, as an expression of Husserl's awareness of our historical limitations, where meanings are sometimes concealed from humans because of their socialconceptual surroundings, then we see that the notion of insight can be productive in a sense quite different from the static perspective. To repeat, when this second dimension of productive fulfillment occurs, what is brought to a subject's attention is something which did not, strictly speaking, exist prior to the individual's reflective grasp.

We can see how this productive notion of fulfillment works by modifying the significance of a few of the terms used above. The consciousness of identity, which within the first account is a reflective grasp of an already operative relation, is now a separate act of intention which precedes the realm of intuition. Here the dynamic moment of fulfillment would actually occur at the point when an empty intentional act meets with its object for the first time. In light of such a reading, Husserl says,

We can readily do justice to the obvious phenomenological difference between the static and the dynamic fulfillment.... In the dynamic relationship the members of the relation, and the act of recognition which relates them, are disjoined 
in time: they unfold themselves in a temporal pattern. In the static relationship, which represents the lasting outcome of the temporal transaction, they occur in temporal and material coincidence. There we have a first stage of mere thought (of pure conception or mere signification), a meaning-intention wholly unsatisfied, to which a second state of more or less adequate fulfillment is added, where thoughts repose as if satisfied in the sight of their object, which presents itself, in virtue of this consciousness of unity, as what is thought of in this thought, what it refers to, as the more or less perfectly attained goal of thinking (LI, 695; boldface added).

What is particularly intriguing about this passage is Husserl's reference to time. A transaction between, as Husserl says, a mere thought, i.e., a purely empty grasp, and an object actually takes place. In such an instance, a subject gains a moment of insight which is not a mere recognition, as when something which has already been experienced is raised to a higher (i.e., nen') level of awareness." Rather, this temporal transaction seems more like the experience of a scientist who creates a hypothesis regarding how the object of experience must be and goes out to test that hypothesis one step at a time. In Husserl's words, there are moments of intentional fulfillment which really take place in time and which are added piece by piece to the subject's grasp through encounters with an object of experience.

That is the notion of productive-dynamic fulfillment which concerns us. It contrasts with the former notion of dynamic fulfillment because the subject's empty grasp is no longer like an already settled awareness of non-present perspectives of the object. This notion of emptiness relates to the idea that the subject is not sure whether or not there is, in fact, an intuition which can satisfy the intention. Upon this characteristic of emptiness, the notion of fulfillment captures the productive dimension of intentional life which grows through experience by actually gaining insights into the world which no one has grasped before. We are intimately 
interested in this dimension of Husserl's notion of dynamic fulfillment, where intuitive moments satisfy an intention for the first time. Unfortunately, this transaction between a purely empty intention and intuition has a hard, perhaps impossible, time working within Husserl's solipsistic framework.

Although Husserl's account contains the possibility for showing how this notion of dynamic fulfillment could work, he misses his opportunity when he pulls away from the communicative model into the solitary life of the speaker." By going inv'ard, Husserl limits the analysis to the contents of an individual's intentional act and therefore misses the opportunity for showing how a purely empty intention is possible.

We can now turn to Ricoeur's notions of the text and narrative-both of which are based upon a communicative sharing of reference - to show how to make sense of Husserl's appeal to a purely empty intention and, hence, to show how dynamic fulfillment, as the occurrence of a totally new insight, can occur.

\section{Text, Narrative, and the Extension of Intention}

Let us begin with the first problem mentioned above: the intersubjective dimension. Ricoeur's interest in the way texts influence an individual's grasp of the world, while limiting the universalistic implications of the notion of knowledge, captures the sense of intersubjective insight which surrounds Husserl's notion of knowledge."

Texts represent, for Ricoeur, a common bond between people. Since texts allow individuals to extend their scope of reference in the same ways, ${ }^{12}$ the text is that intersubjective resource which makes possible a claim to know the world as others do. ${ }^{13}$ Admittedly, this realm of intersubjective insight is really limited to those people who have actually read and understood the same text or texts; but, the fact remains that this level of insight is not ideally limited to any group of people. The notion of the text includes the idea that a scope of reference can be adopted by anyone who takes the time to engage the same material. So, even if the claim to know the world from within a particular fiame of reference is really limited to certain people, this claim to know is, in principle, available to anyone who can access the meaning of the text. 
As a means for addressing the question regarding an intersubjective grasp of the external world, Ricoeur's interest in the text puts us on track. However, the issue of fulfillment is not addressed at this level. We are only told how an individual's grasp of the world can be extended in the same way as other individuals. It is Ricoeur's notion of narrative, as an extension of his concern for the text, which shows how fulfillment is possible.

Let us first draw attention to the fact that narratives are written accounts about what people do. Narratives are, therefore, an intersubjective resource depicting how people act within the world. When a person reads the narrative of another person, e.g., a narrative which depicts a different or unfamiliar way of acting, the reader is given references about the world which increase his or her grasp of the world. This increase in the subject's scope of reference is not, however, a full blown knowledge given that what the subject now understands about the world is a hypothetical rendering of the world for the reader. Ricoeur calls this the as if dimension of the reader's experience with textual references (IT, 34-37). ${ }^{14}$ Yet, we must not see this lack as negative. The lack is positive since new' moments of fulfillment are made possible for the individual through the accounts of others. Now we can show how the notion of fulfillment relates to this intersubjective-narrative framework.

By focusing on how some narratives are related to what people really do the issue of fulfillment is transformed from Husserl's interest in perception to a concern for action. ${ }^{15}$ Narratives are to be understood as accounts which are handed down through a linguistic community which prescribe in advance how the real world is to be acted upon by individuals who adopt the narrative. A narrative is not, then, simply a story. A narrative is an account of how discrete actions link together as means to accomplish a goal. It is the actual accomplishment of the goal which reveals how a narrative can be fulfilled in reality. The fact that things can really be accomplished by following the dictates of the narrative shows that the narrative is correlated to reality. (We can, for example, distinguish between science fiction and real science by knowing what can and cannot really be accomplished by people.) Now, before we explain how this notion of narrative allows us to account for a productive-dynamic moment of fulfillment, let us see how it 
also adds an important intersubjective layer to the issue of static fulfillment.

Husserl is capable of explaining how static fulfillment is possible only from a solipsistic perspective: a subject anticipates a moment of fulfillment because the individual has previously experienced the object. Ricoeur's notion of narrative adds another layer into this idea of static fulfillment: the subject, by learning a narrative framework, grasps how others in the field currently take the world to be. The subject who engages the world according to the structure of a narrative gains insight into an already settled correlation between structure and world thus coming to know the world as others already do. In this case, the subject certainly gains an insight into the world but what the subject learns is not necessarily something new. What is revealed to the subject is how the real world is already mediated by a narrative coherence. ${ }^{16}$ At this point, we can turn to the issue of a dynamic fulfillment.

The most important pay-off in our analysis comes from showing how Ricoeur's account of narrative moves beyond the analysis of an already settled correlation between narrative and action and into the dynamic notion of fulfillment. ${ }^{17}$ Here the individual person raises in importance by making possible really new, i.e., really empty, insights into the world. Of course, the subject does not gain a purely empty insight into the world e.r nihilo. Within the analysis of narrative, it is the impact other narrative frameworks can have over the subject's own conception of how action is structured which allows the insight. Nevertheless, the insight is personal to the extent that a really new proposal for acting upon the world can come from an individual's unique fusion of narratives. The dynamic notion of fulfillment is literally set into motion by demanding from the subject a real action to follow from the proposal for acting in a new way. Ricoeur says, "Reading appears by turns as an interruption in the course of action and as a new impetus to action" (TN III, 179). ${ }^{1 \times}$ The emptiness demands that the subject act upon the world in order to see if, in fact, the narrative is fulfillable in the world.

Admittedly, Ricoeur's concern for socially developed narratives and the fulfillment of narratives in action changes the scope of Husserl's notion of intentionality quite drastically. 
However, Ricoeur's notion of narrative retains the basic framework of Husserl's analysis and we get a better understanding of Ricoeur's account by seeing this similarity.

Husserl is committed to the idea that the subject knows the external world as others do. Here, Ricoeur's notion of narrative helps overcome the solipsistic framework which blocks Husserl's account. Ricoeur is committed to the idea that the significance of a narrative is only known through a personal comprehension of how narrative and action unite. Here we can say that Ricoeur retains Husserl's interest in the subject and provides an answer to a very difficult question. Husserl asks, "How are we to understand the fact that the intrinsic being [an sich] of objectivity becomes 'presented,' 'apprehended' in knowledge, and so ends up becoming subjective?" (LI, 254; brackets added) By recasting the issue of objectivity around what is intersubjectively graspable, Ricoeur shows how what is objective can be apprehended by an individual's intention since it is the real flesh and blood subject who is the very site of knowledge: the one who knows a narrative is the one who can put that narrative into action."

\section{NOTES}

' Edmund Husserl, Logical Investigations, vols. I \& II, trans. J. N. Findlay (New Jersey: Humanities Press, 1970). Hereafter LI.

2 Edmund Husserl, Cartesian Meditations, trans. Dorian Cairns (Dordrecht: Kluwer Academic Publishers, 1995). Hereafter CM.

${ }^{3}$ Husserl says, "By virtue of the ... communalization of constitutive intentionality, the transcendental intersubjectivity has an intersubjective sphere of ownness, in which it constitutes the Objective world.... (CM, 107).

+ For an excellent account of Husserl's ability to incorporate intersubjectivity into his phenomenology, see: Kathleen M. Haney, Intersubjectivity Revisited: Phenomenology and the Other (Athens: Ohio University Press, 1994).

${ }^{5}$ Husserl pulls away from the communicative relationship between interlocutors and focuses upon the speaker's grasp of his or her own intention since only the speaker has an unmediated grasp of what he or she wants to say (LI, 277-279). See also Rudolf Bernet, "Husserl's Theory 
of Signs Revisited," in Edmund Husserl and the Phenomenological Tradition, ed. Robert Sokolowski (Washington D.C.: The Catholic University Press, 1988), 6-10.

"Husserl's interest in how the subject's intention is built-up through perceptual experience is captured in this passage: "The features which enter into perception always point to completing features, which themselves might appear in other possible perceptions [Wahnehmmingen], and that definitely or more or less indefinitely, according to the degree of our 'empirical acquaintance' [Erfahrungskenmmis] with the object" (LI, 700 ; brackets added and translation modified). See also Husserl, LI, 309310,839 .

${ }^{7}$ For those readers familiar with the $\mathrm{CM}$, this problem is related to what Husserl calls the ego's sphere of ownmess.

' The term emptiness, in Husserl's account, is ambiguous. It can mean at least three things. First, one can have an empty grasp of something simply because the thing which is grasped is not present. In this regard, the intention lacks a certain liveliness (Lebendigkeit) [LI, 734-5]. Second, some intentions simply have no extension, i.e., no real, extra-signitive, members (LI, 692). Third, the term empty can refer to a subject's grasp of a meaning. Here we might say that the subject does not know whether or not the ideality which he or she grasps is, in fact, fulfillable in reality. This notion of emptiness fits best when explaining how a subject comes to an awareness of meaning which is totally new not just for the subject but for any living human.

"Findlay's decision to translate Husserl's term Erkenmen as recognition makes good sense from the perspective of static knowledge. Recognition conveys the idea that what the subject grasps explicitly in a moment of knowledge is an already settled relationship between intentional grasp and, as Husserl says, intuitive presence.

"1" Husserl goes inw'ard because the listener' $s$ experience of meaning is always deficient: in communication, signs "mean something to [the listener] insofar as he interprets them [sofern er sic eben deutet], but even for him they are without meaning in the special [prägnamten] sense in which verbal signs have meaning: they only mean in the sense of indicating" (LI, 275; brackets added). Ricoeur, as we shall see, capitalizes on this so called deficient experience in his concern for the reader.

"Husserl's concern for a universal insight oversteps the boundaries of what a phenomenology of knowledge can possibly say. Husserl, at times in the LI, argues that the object can be known as it is in-itself. This is most strongly argued when Husserl appeals to the notion of a perfect adequacy which can be reached between subject and object (LI, 726, 729, 763). For excellent critiques of Husserl on this topic, see: David 
Michael Levin, Reason and Evidence in Husserl's Phenomenology (Evanston: Northwestern University Press, 1970), 41-47; Rudolf Bernet, "Perception as a Teleological Process of Cognition," in Analecta Husserliana, vol. 9, ed. A. Tymieniecka (Dordrecht: D. Reidel Pub. Co., 1979), 119-132; David Bell, Husserl (London/New York: Routledge, 1990), 129-142. We take up Husserl's interest in knowledge, then, not from the perspective of grasping the object as it is in-itself but from the intersubjective implication which goes along with any claim to know something.

${ }^{12}$ Ricoeur explains how texts free people from the confines of their own dialogical situation: "This first extension of the scope of reference beyond the narrow boundaries of the dialogical situation is of tremendous consequence. Thanks to writing, man and only man has a world and not just a situation..." (Ricoeur, Interpretation Theory: Discourse and the Surplus of Meaning [Fort Worth: Texas Christian University Press, 1976], 36). Hereafter IT. Ricoeur's notion of world points to an intersubjective coherence which we discuss under the term narrative.

${ }^{13}$ Of course, accessing a text's meaning, i.e., its scope of reference, is not always a simple procedure. Ricoeur accounts for the issue of interpretation which goes along with every textual explanation. Nevertheless, when Ricoeur appeals to the text's world as autonomous he takes this in a positive sense where something stable can survive across historical differences. Ricoeur puts it like this: "[The text] is a kind of atemporal object, which has, so to speak, cut its ties from all historical development. The access to writing implies this overcoming of the historical process, the transfer of discourse to a sphere of ideality that allow' an indefinite widening of the sphere of communication" (IT, 91; brackets added).

it See also Ricoeur, Time and Narrative, vol. III, trans. Kathleen Blamey and David Pellauer (Chicago: University of Chicago Press, 1988), 157-179. Hereafter TN III.

${ }^{15}$ Of course, this change in perspective is not without precedent in Husserl's writings. Husserl says, "(T)his world is there for me not only as a world of mere things, but also with the same immediacy as a world of objects with ralues, a world of goods, a practical world. I simply find the physical things in front of me furnished not only with merely material determinations but also with value-characteristics.... These value characteristics and practical characteristics also belong constitutively to the Objects 'on hand' as Objects [konstitutiv' zu den 'vorhandenen' Objekten als solchen], regardless of whether or not I turn to such characteristics and the Objects (Idecas Pertaining to a Pure Phenomenology and to a Phenomenological Philosophy, First Book, trans. F. Kersten [Dordrecht: Kluwer Academic Publishers, 1982], 53; brackets added). 
"On the notion of revelation, see Ricoeur, "Discussion: Ricoeur on Narrative," in On Paul Ricoetr, ed. David Wood (London/New York: Routledge, 1991), 180. Revelation defines a mode of knowing which correlates to temporal realities rather than spatial realities. Temporal realities include: time-periods, events, horizons, worlds, etc. These second-order references are not open to a strict empirical analysis as are first-order references. See Robert D. Sweeney, "Reference and Refiguration in Ricoeur's Hermeneutics," Proceedings of the American Catholic Philosophical Association 62 (1988): 71-79.

${ }^{17}$ In Ricoeur's language, he is interested in showing how an individual can refigure action by first understanding how actions are already configured by narratives. See Ricoeur, Time and Narrative, vol. I, trans. Kathleen McLaughlin and David Pellauer (Chicago: University of Chicago Press, 1984), 52-77.

${ }^{18}$ Cf. S. H. Clark, Paul Ricoeur (London/New York: Routledge, 1990), 194.

1" An earlier version of this paper was presented at the thirtieth annual meeting of the Husserl Circle (Seattle University). I wish to thank the anonymous reviewer who critiqued that submission and helped me to formulate a couple of the key points discussed in this paper. 